\title{
Analysis of hypocycloid drive application in a high-pressure fuel pump
}

\author{
Mateusz Bor ${ }^{1}$, Tomasz Borowczyk ${ }^{1}$, Marek Idzior $^{1}$, Wojciech Karpiuk $^{1, *}$, and Rafat Smolec ${ }^{1}$ \\ ${ }^{1}$ Poznan University of Technology, Faculty of Machines and Transport, ul. Piotrowo 3, 60-965 Poznan, Poland
}

\begin{abstract}
This paper undertakes the problem of applying a hypocycloid mechanism in the drive of pumping sections of high-pressure pumps for Diesel combustion engines. The authors have reviewed existing pump drive mechanisms, analyzed the weak links in existing solutions and discussed the latest trends in common rail systems. Further sections describe the design of a pump utilizing a hypocycloid mechanism, demonstrate beneficial functional features and present selected results of the assembly's dynamic simulation. As a result of work, a pump model was developed, with operating parameters that do not deviate from those of the latest solutions of leading manufacturers, simultaneously eliminating the greatest flaws of existing pumps that lead to their premature wear.
\end{abstract}

\section{Introduction}

Common rail (CR) injection systems have been universally applied in passenger car engines for twenty years. Moreover, they are applied on a wide scale in trucks, machinery and stationary engines. The term common rail refers to the fuel rail of the injection system. Its architecture is based on three primary elements: a high-pressure pump, fuel rail and fuel injector (Fig. 1). The system owes its most important and beneficial feature to its design, which is the capability of injecting fuel under high pressure regardless of the engine's crankshaft position.

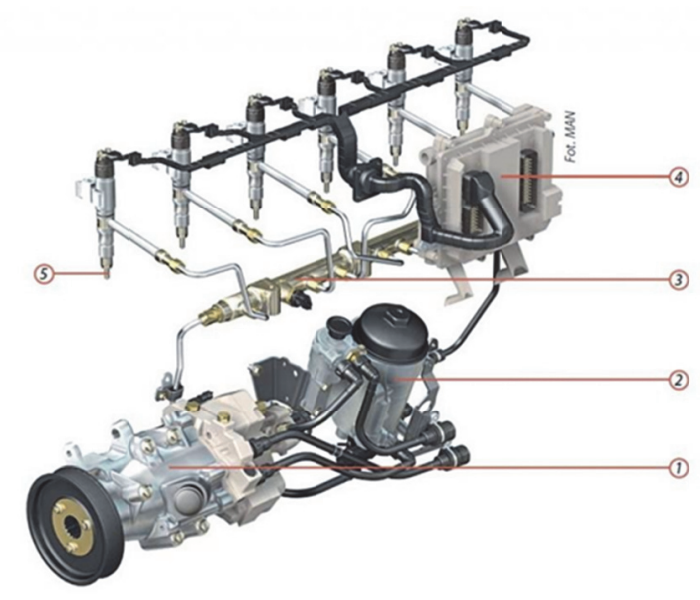

Fig. 1. Common rail system in a truck with its most important subassemblies: 1 - high-pressure pump, 2 - fuel filter, 3 - fuel rail, 4 - control system, 5 - injector [1].

On the European market, common rail (CR) systems displaced volumetric pumps (VP) and UIS/UPS injector systems. In contrast to other generations, CR enables multiple division of a batch, regardless of the crankshaft's position and speed. Batches can be divided into as many as 10 parts with the help of the latest solutions (CRS3-27 from Bosch). This precise injection control system, effected by electromagnetically or piezoelectrically controlled injectors, makes it possible to significantly reduce emissions into the atmosphere and interoperate with external emissions purification systems. In engines with large capacities, designed for heavy-duty machinery and trucks, injection pressures reach up to $300 \mathrm{MPa}$. High pressure makes it possible to obtain very small fuel droplets, which combust more easily due to increased droplet surface area. High pressure also reduces the duration of individual injection phases, leading to better control of the combustion process. The fuel pump is responsible for generating high pressure in the system. In common rail systems, these pumps are designed as radial sectional pumps with one, two or three pumping sections. In the case of trisectional pumps, the angle of aperture between cylinders is $120^{\circ}$, bi-sectional pumps usually have a Continental system or cylinders are positioned on perpendicular axes. Pumps with a greater number of pumping sections, positioned in rows, are also encountered in trucks. Depending on the application, CR pumps can be integrated with a low-pressure feed pump. Two possible types of radial sectional pumps can be distinguished according to design:

- with an external cam (Delphi DFP1, Denso HP2),

- with an internal cam (numerous solutions, including the latest designs, e.g. Bosch CP4i).

The use of fuel as a lubricant is a common feature of high-pressure pumps applied in passenger vehicles from all manufacturers. Over the course of the pump's work, fuel is supplied to pumping sections and the drive system (camshaft). Thus, the proper lubricating parameters must

Corresponding author: wojciech.karpiuk@put.poznan.p1 
be ensured in order to generate a film and separate contacting surfaces. Numerous analyses and studies of damage and wear on contacting parts, conducted by the authors, have led them to conclude that insufficient fuel quality is the primary cause of pump defects. However, it should be noted that improper design is also a factor fostering the initiation and progression of pump damage, with respect to both the feed pump and high-pressure pump. The most important causes of pump wear are [2]:

- improper quality (lubricity) of fuel at fuel stations,

- presence of abrasive grains originating from parts of injection systems,

- application of fuel filters of insufficient quality, or insufficiently frequent filter replacement.

The lubricity of fuels is determined using the HFRR method. It is based on determining the maximum diagonal of an impression formed by a ball wear test, using the tested fuel as a lubricant. This chart (Fig. 2) presents the dependency between runtime and wear of pump elements (expressed as loss of material layer in $\mu \mathrm{m})$. As can be seen, there is a strong dependency between the HFRR parameter and the lifetime of pump parts. At HFRR $>600 \mu \mathrm{m}$ there is very sudden wear growth, leading to the pump's destruction. For this reason, it is very important for the fuel sold at fuel stations to meet the requirements of standard PN-EN 590:2013-12, according to which the upper limit of the HFRR parameter is $460 \mu \mathrm{m}$. The introduction of FAME additives to Diesel effectively improves its lubricating properties due to the high fatty acid methyl ester content in rapeseed oil, which is below $200 \mu \mathrm{m}$ [3]. The considerations above show that increasing pump lifetime can be achieved by:

- providing independent lubrication of the sectional drive system,

- changing or modifying the cam system used until now in order the reduce the influence of the applied lubricant.

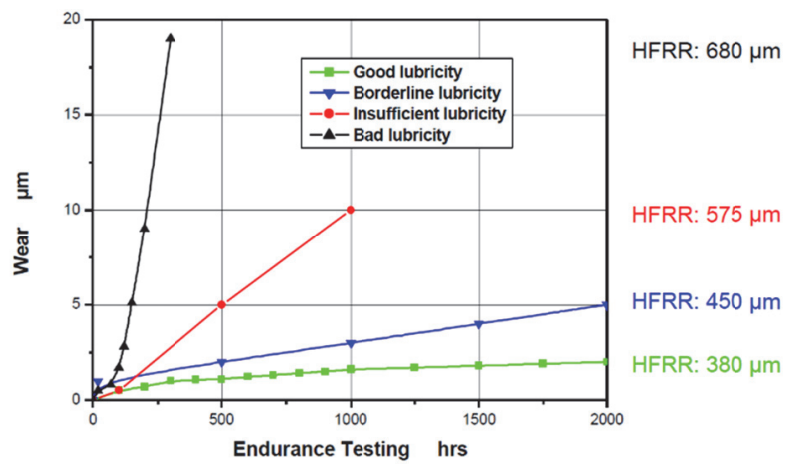

Fig. 2. Wear of pump parts over the test's duration [1].

\section{Analysis of selected design solutions}

\subsection{Bosch pumps}

Bosch is among the leading manufacturers of $\mathrm{CR}$ systems. The first generation of Bosch common-rail systems made its debut in 1997, in motor vehicles sold by Fiat. More high-pressure pump solutions appeared as the field grew, and they include:

- $\mathrm{CP} 1$ - also in the $\mathrm{CP} 1 \mathrm{H}$ variety, with $160 \mathrm{MPa}$ maximum operating pressure,

- $\mathrm{CP} 2-$ used in trucks,

- CP3 - modernized design of CP1, $200 \mathrm{MPa}$ maximum pressure,

- CP4 - the latest mono- or bi-sectional pump, 270 MPa maximum pressure.

The functional problems of CP1 have been discussed at length in the literature of that field. The defective design of the piston drive system, which are additionally loaded by a lateral force, often leads to destruction of the entire pump. Workshop practice shows that the trisectional CP3 from Bosch is the most durable pump, where the flaws of CP1 were eliminated by introducing an additional sectional guide.

CP4 is currently applied in vehicles equipped with the latest Bosch injection systems. In contrast to earlier generations, it has one or two pumping sections with a $90^{\circ}$ angle of aperture, performing two work cycles per revolution of the crankshafit (Fig. 3). The compact dimensions achieved by limiting the number of pumping sections and changing the drive method are characteristic.
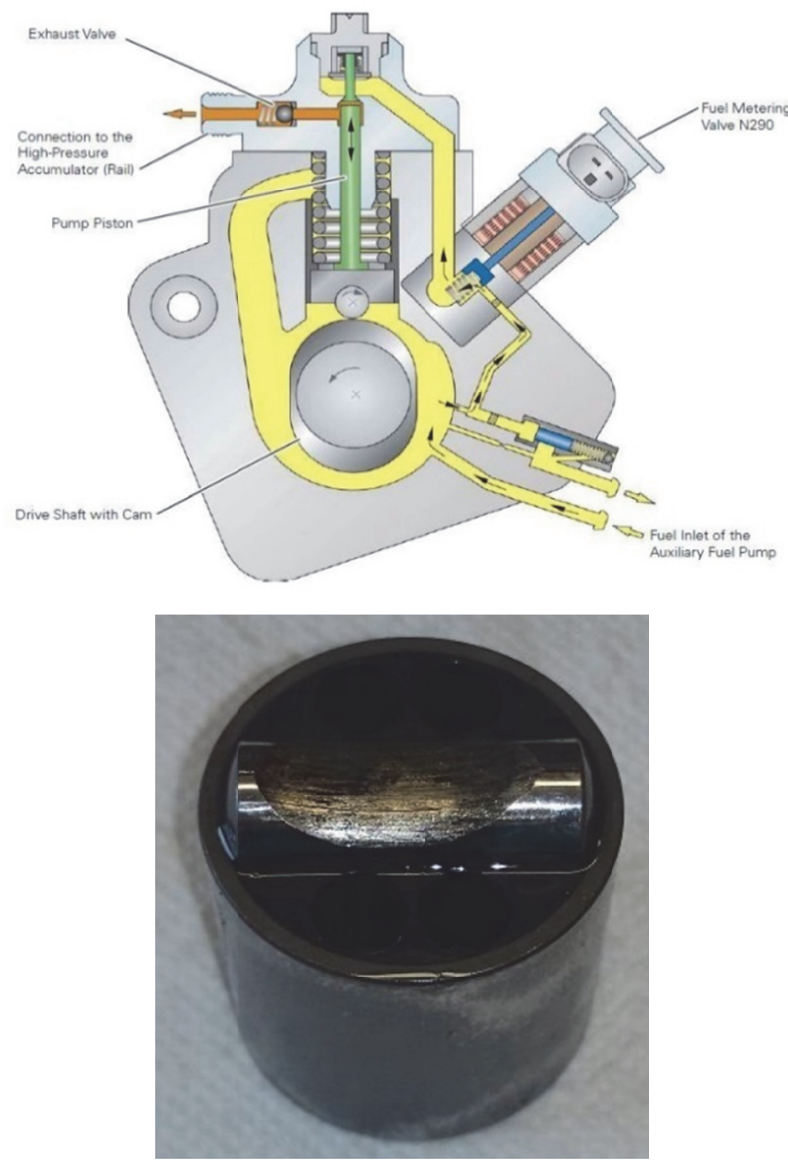

Fig. 3. Cross-section of CP4 and damage of push roller [4].

In the case of vehicles with low power, limiting the number of sections to one is very beneficial on account of the friction losses in the system. Furthermore, the 
reinforced structure of the body, head and elements of the drive system (including larger bearings) makes it possible to generate pressures reaching up to $270 \mathrm{MPa}$ (e.g. CP4-27/2). CP4 is selected to match the engine so that there is one fuel compression cycle per engine work cycle. This is made possible by ensuring stable high pressure in the fuel rail and reducing pressure pulsations significantly. The pump's discharge is adjusted analogously as in previous generations, using the fuel batching valve.

An improper cam-roller-pusher solution is a fundamental flaw of this generation of pumps. The applied roller significantly contributed to reducing forces in the mechanism by utilizing rolling friction, however the pusher with a circular cross-section had a tendency to rotate, particularly when contaminants were present, friction was elevated by inferior fuel quality or insufficient fuel quantity. When the roller's position changes to perpendicular relative to the shaft's axis, rolling friction changes to sliding friction, which exponentially accelerates the mechanism's wear. Metal filings from the damaged roller destroy inter-operating elements of the pumping section, and cause seizing when they penetrate into injectors $[4,5]$. When replacing the fuel filter in vehicles equipped with $\mathrm{CP} 4$, it is particularly important to deaerate the fuel system properly using a diagnostic tester. Improper deaeration leads to fuel deficiencies in the drive mechanism and can cause the roller's position to change. The scale of the problem is large enough that an independent company (2microntech) has developed a set dedicated for the CP4, including a filter purifying fuel flowing from the drive system to the pumping section (Fig. 4). The set also contains a filter indicator and makes it possible to replace the filter insert after filtering holes become clogged. Thanks to the application of an additional filter, it is possible to avoid failures of other elements of the injection system.

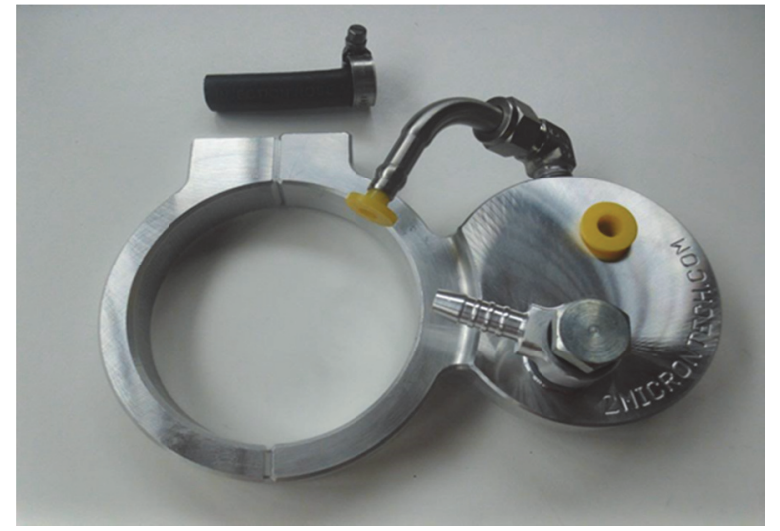

Fig. 4. Additional filter with filtering efficiency up to $2 \mu \mathrm{m}$ for application in CP4 [4].

\subsection{Delphi pumps}

Among the many manufacturers of CR systems, only Delphi and Denso decided to apply rotary pump systems in the first generation. Individual pump varieties are abbreviated as follows:
- DFP1 - rotary injection pump for first-generation CR,

- DFP3 - bi- or tri-sectional radial pump,

- DFP6 - the latest generation of monosectional pumps, used in HDi DW10F engines .

Due to the low number of applications and short production period, no typical operational problems of DFP6 have been defined at this time. However it should be noted that DFP3, boasting a longer presence on the market, did not exhibit serious defects and can be considered a durable design. The functional problems of these pumps are limited to replacement of the discharge adjustment valve, in which the fuel mesh filter is usually damaged.

In the rotary DFP1, similarly as in Bosch's CP4 solution, a system with a roller was used to drive the piston. In this case, the head and pumping sections are stationary, while the pistons' reciprocating motion is forced by an external cam generating four piston work cycles per cam revolution. As a result of abrupt cam ascension and under conditions of insufficient lubrication, the surface of the material is damaged (flaking) (Fig. 5). This phenomenon is exacerbated by the high number of work cycles, which also increases the material's fatigue wear. Filings only $2 \mu \mathrm{m}$ in size are transported into the fuel rail and injectors along with fuel, leading to damage. Fuel also enters the fuel vessel via overflow. For this reason, if a DFP1 is damaged, all injection apparatus must be replaced, including fuel conduits and the fuel vessel. Failure to do so carries the risk of leaving filings in the system, which will damage new elements [5].

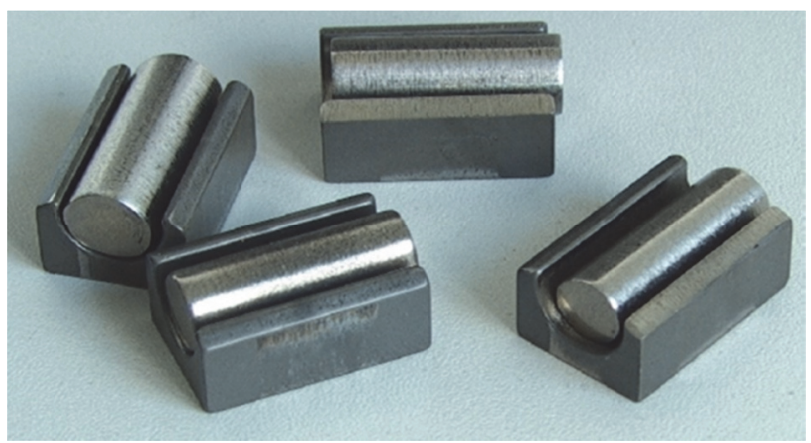

Fig. 5. Worn rollers in DFP1 [1].

\subsection{Continental/VDO pumps}

Pump generations are not distinguished by any symbolic designation in the Continental group. Nevertheless, these pumps can be separated into generations on the basis of design changes:

- old pumps, tri-sectional,

- new pumps, bi-sectional.

In the case of Continental pumps, feed pump failure is the primary source of damage. This is a vane pump, essentially consisting of a body, inner wheel and vanes that are slid into it. The pump is mounted on the main shaft and vanes are pressed toward the body by the centrifugal force of rotation. Their light weight, in combination with contaminants in the fuel, is the cause 
of jamming, when the centrifugal force is lower than the forces of cohesion/friction between a vane and the wheel. Loss of discharge occurs as a result of leaks [6]. Reduced discharge leads to deterioration of lubrication in the drive and reduces the pump's volume output. This is slightly corrected by the discharge adjustment valve, which places additional load on the pump. The effect is seizing of contacting surfaces of the cam and pivot, blocking of the pump's pumping sections and damage to injectors.
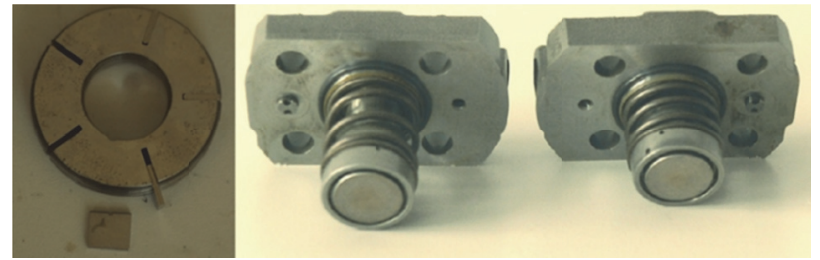

Fig. 6. Feed pump with vanes and blocked pumping section [1].

\subsection{Directions of development}

Increasingly high requirements are being posed towards modern Diesel engines due to emissions standards imposed on manufacturers. The current Euro 6 standard requires the application of numerous emissions purification systems external to the engine, such as solid particle filters and SCR reactors. The injection system plays an equally important role in reducing exhaust emissions, and at the same time, it should ensure stable interoperation with emissions purification systems. In reference to injection pumps, this means creating the possibility of feeding fuel under high pressure regardless of revolutions. At the same time, one must account for the resistance arising from interoperation of parts, which grow as pressure increases. Modern pump designs should also be less susceptible to damage caused by fuel.

A tendency to reduce the number of pumping sections to one while simultaneously reducing exterior dimensions can be observed in the general design of pumps from all leading manufacturers. Figure 7 presents selected pump designs, which, besides CP4i, are already applied in engines meeting the Euro 6 emissions standard. Two essential goals are achieved by reducing the number of sections. First of all, the contacting surface of interoperating elements is significantly reduced, thanks to which internal friction is greatly reduced. Thanks to this friction reduction, the power consumed by the pump is strongly limited, up to as much as $5 \mathrm{~kW}$, which is a significant portion of the power generated by the vehicle's engine.

The second goal of reducing the number of pumping sections is to facilitate synchronization of the pumping process with the injection process. In solutions utilizing tri-sectional pumps applied until now, non-uniform injection pressure was caused by a lack of equality between the number of pumping cycles and injection cycles, and over the course of exploitation - by varying efficiency of each section. In effect, varying spray jet atomization parameters were obtained as early as the fuel feeding stage. Monosectional pumps can be adapted to a $3,4,6$ or 8 -cylinder engine by changing only the transmission ratio between the crankshaft and the pump's shaft. For 8-cylinder engines, bisectional pumps with a fork configuration are also encountered (Bosch CP4.2), in which each section feeds one row of cylinders.
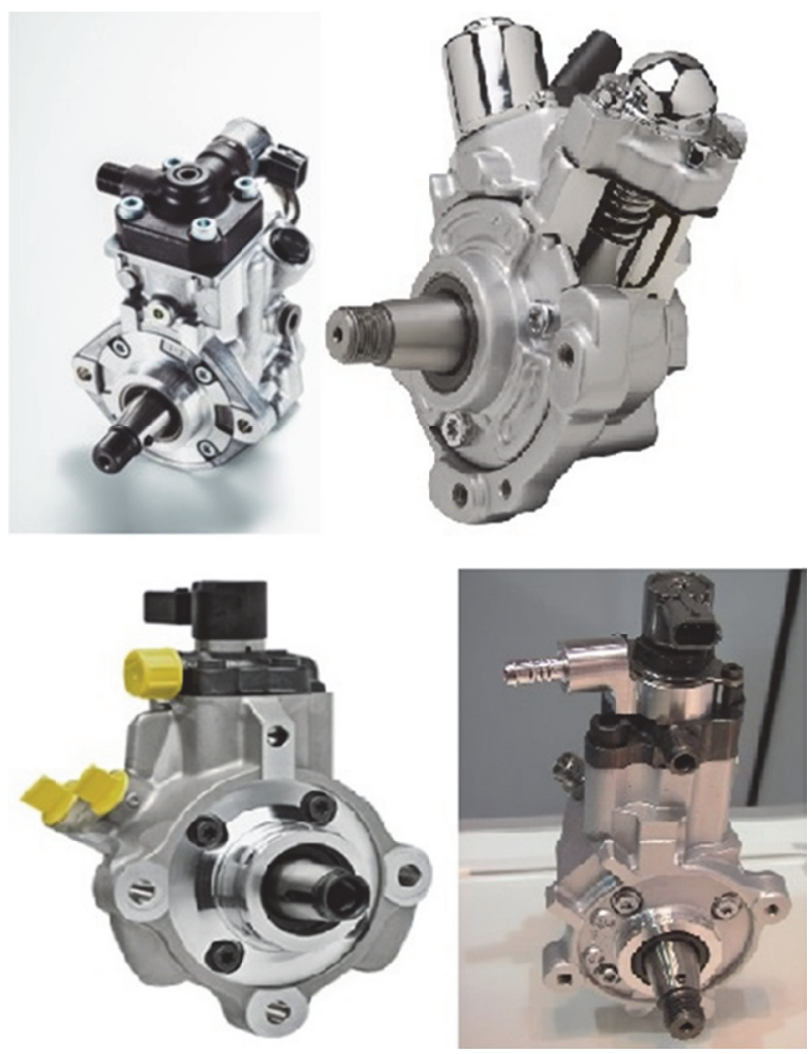

Fig. 7. Latest solutions of pumps for motor vehicles (from the left) : Denso HP5S, Delphi DFP6, Continental DHP1, Bosch CP4i [3].

The problem of pump lubrication, extremely important from an operational perspective, was solved by using motor oil in the CP'4i design. The solution of lubricating the pump with motor oil is commonly applied in trucks, where the kilometerage between repairs may reach up to several hundred thousand kilometers. Motor oils have much better lubrication and viscosity parameters, thus enabling significant reduction of cases where pump elements are worn pathologically. Ensuring that pumping sections are tight (leakproof) is a significant problem, and CP2, used in trucks, is a good example of this, as motor oil dilution was a frequent phenomenon in this design. At this time, the details of the CP4i design are unknown, nevertheless the manufacture declares motor oil leaks at a level not exceeding $1 \mathrm{ml}$ per million cycles, with $95 \%$ hydraulic efficiency [7].

To improve pump efficiency, manufacturers are planning to change the method of discharge control. In traditional CR solutions, a discharge adjustment valve is installed in the body (also visible in the Delphi DFP6 solution in Fig. 7). This valve is controlled by PWM, or pulse-width modulation. Depending on the desired discharge, pulse-width is increased or decreased, causing 
the valve to reduce or increase the cross-section of the fuel channel feeding the pumping section. The new concept calls for direct control of section filling in every work cycle. During the suction phase, the valve is open and makes it possible to fill the pumping section completely. After the piston passes through its extreme lower position, the valve is closed only when the requirement amount of fuel is found in the section. As the piston ascends in its stroke, excess fuel return to the feed conduit via the inlet channel. The advantages of this solution should be sought, above all, in the capability of real-time pump control. It is possible to freely increase or decrease discharge in consecutive compression cycles, which, in combination with synchronization of the pump shaft's position with the crankshaft, can be applied to reduce harmful volumes harmful to the fuel rail (reduction of hydraulic phenomena). Furthermore, pumps performing two work cycles per section per shaft revolution are under high loads, both mechanical and thermal. Complete filling of a section contributes to the internal cooling of the pump's cylinder.

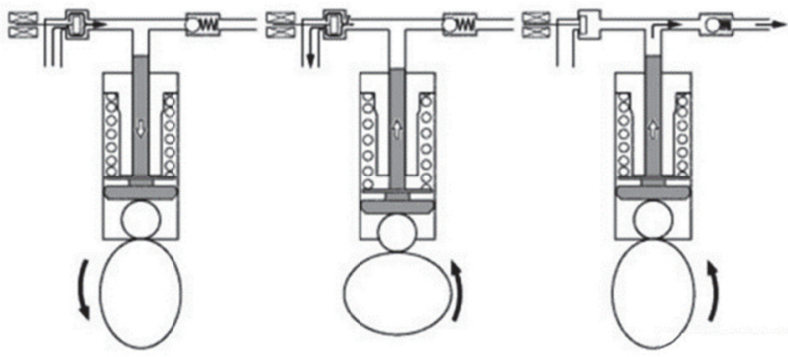

Fig. 8. Pumping diagram of a Denso GP5S with a direct-action valve [5].

The changes proposed in prototype CR systems fall outside of the subject of pump optimization and also call for the application of pumps with completely different hybrid designs. Many manufacturers have presented a solution based on the application of components typical for UIS/UPS systems and CR (Fig. 9). Fuel vessels of significantly diminished volume, interoperating with injectors typical for a CR system, are a characteristic feature of this approach. Pumps are situated in the head and powered in a manner typical for a unit injector system. Another solution is a hybrid system, in which some injectors are classical CR injectors and the rest (usually in a 1:1 ratio) are electronically controlled unit injectors connected to the $\mathrm{CR}$ injectors by the fuel vessel. In such a system, the unit injector performs the role of both individual injection unit for a given cylinder and pump for the rest of the system. An undoubted advantage of solutions like this are their limited overall dimensions, which make it possible to situate all subassemblies under the valve cover. In their new CR pump designs, Delphi and Bosch provided the possibility of installation directly in the head. The pumping section with the roller and control valve constitute a module that can be placed in the body of a traditional pump or directly in the head, with a camshaft drive (Fig. 9). This method of fitting the pump enables easy lubrication of the drive system through the crankshaft's oil system while simultaneously maintaining small exterior dimensions of the drive unit. It should be emphasized that the presented solutions are prototypes, and the actual benefits of applying such systems are still unknown. Considering the presented problems and directions of development, pressure will continue to rise in future systems, and pump designs will be simplified, with an oil lubrication system and perhaps systems being a hybrid of existing solutions will be developed.
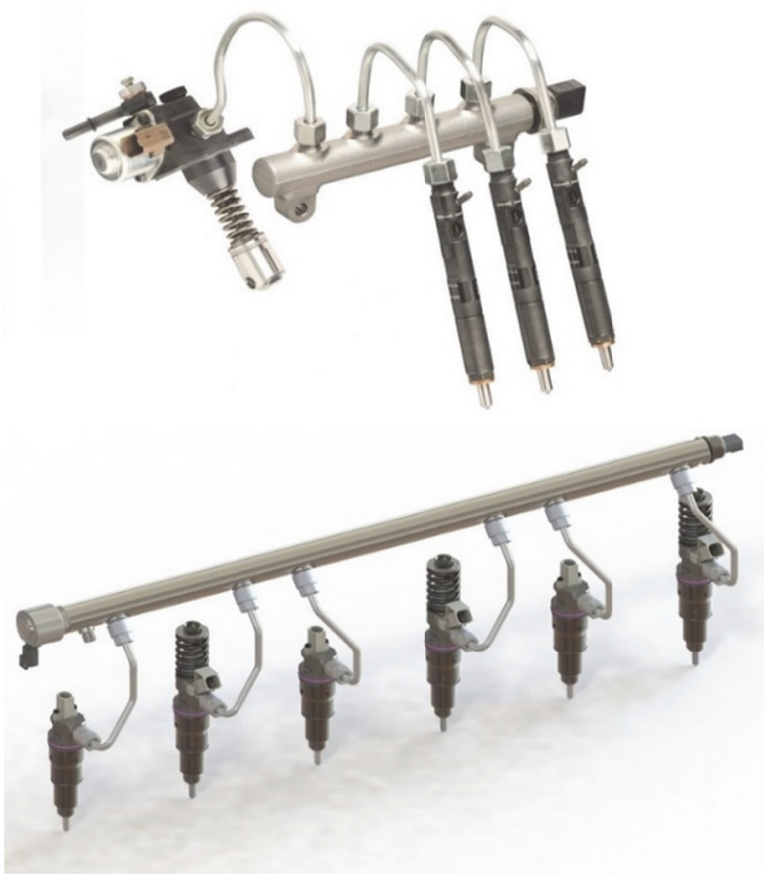

Fig. 9. Prototype Delphi systems : UP-CR on the bottom, common rail on the top with modular pump interoperating with the crankshaft [1].

\section{Utilizing a hypocyclloid drive in a high- pressure fuel pump}

\subsection{Origins}

The hypocycloidal transmission with interior toothing was already patented in the 19th century. Depending on the selected wheel diameters, it made it possible to obtain various curves resulting from its resultant motion. Its popularity was limited by design and economic aspects. At the time, these drives and engines did not transmit high powers or torques, and the lifetime of subassemblies was very limited. So, the problem of optimizing the design of a system converting reciprocating motion to rotation was not as significant as it is today. Moreover, in reference to the traditional slider mechanism, manufacturing a hypocycloid transmission would be more expensive and more difficult due to the high requirements relating to its teeth.

For many years, designers have sought possibilities of applying a hypocycloid gear in combustion engines. This system would replace the slider-crank mechanism used until now. The absence of lateral forces acting on the guided element is a great advantage of hypocycloids 
on account of the crank system. It is accepted that lateral forces make up approx. 10\% of the axial force generated by the pressure in the cylinder. Significant lateral forces generate very high powers, and pressures, from one cylinder. Eliminating the effects of their action is a very large field of study for engineers concerned with combustion engine design $[8,9]$.

One example of a hypocycloid transmission is the Wiseman engine patented in 2001 (Fig. 10). As part of work performed at the company, an engine with 10, 20 and $30 \mathrm{HP}$ was developed and an engine with approx. 1 HP was made and tested. The design was based on the classical slider-crank engine. The experiment's results showed power and efficiency parameters that were very similar to the base engine, however at the same time, high potential for optimization and improvement of indicators was observed.

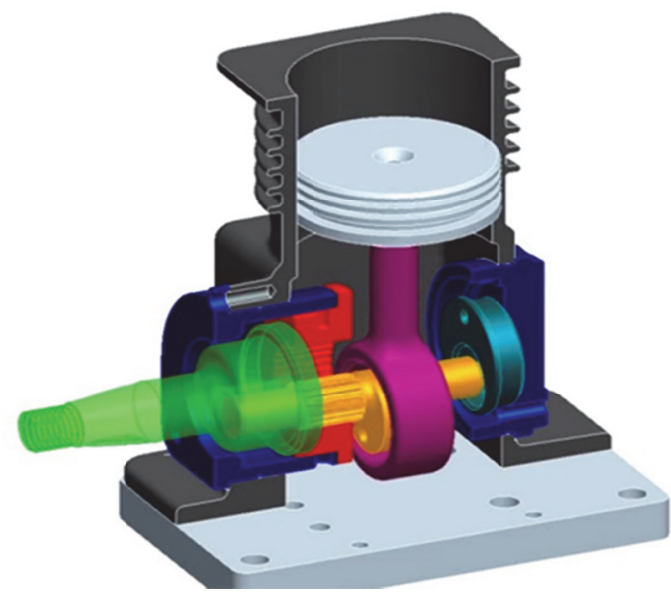

Fig. 10. Wiseman engine with hypocycloid transmission in cross-section [6].

In addition, the engine's overall dimensions were limited significantly by using one of the hypocycloid's beneficial features, which is high pitch compared to the system's size. Unfavorable efficiency and power parameters were obtained for the two-stroke engine, due to the large volume of the crankcase, resulting in low pressure. Numerous patent applications relating to designs utilizing a hypocycloid drive demonstrate the system's high potential and benefits of its application. Many attempts to implement the hypocycloid are being undertaken, in order to replace the aforementioned slider system or the cam drive. The hypocycloid can transmit power in two directions, which means it can be the system driving the working element and the power takeoff (in the case of an engine - the piston), which is a significant advantage in comparison to the cam - pusher system.

\subsection{Description of the drive}

The hypocycloid transmission consists of two wheels the larger wheel $(R)$ has interior toothing and the smaller wheel $(r)$ has exterior toothing. Torque is applied to the smaller wheel, making it turn, however the larger wheel cannot rotate around its axis. The smaller wheel moves over the circumference of the larger wheel, and any point on the smaller wheel's radius moves in a curve called the hypocycloid. To create the working drive of the pump, a hypocycloid transmission with a gear radius ratio of $R / r=2$ was applied. This selection of wheels makes it possible to achieve resultant linear motion, as per Copernicus's Theorem: "Consider two circles of radii $\mathrm{R}$ and $R / 2$ with the smaller one rolling inside the bigger circle without slipping. Any fixed point on the circumference of the small circle traces a straight line segment - a diameter of the big circle." Figure 11 presents a diagram of the transmission, and the line on which the mechanism's sliding element moves is marked.

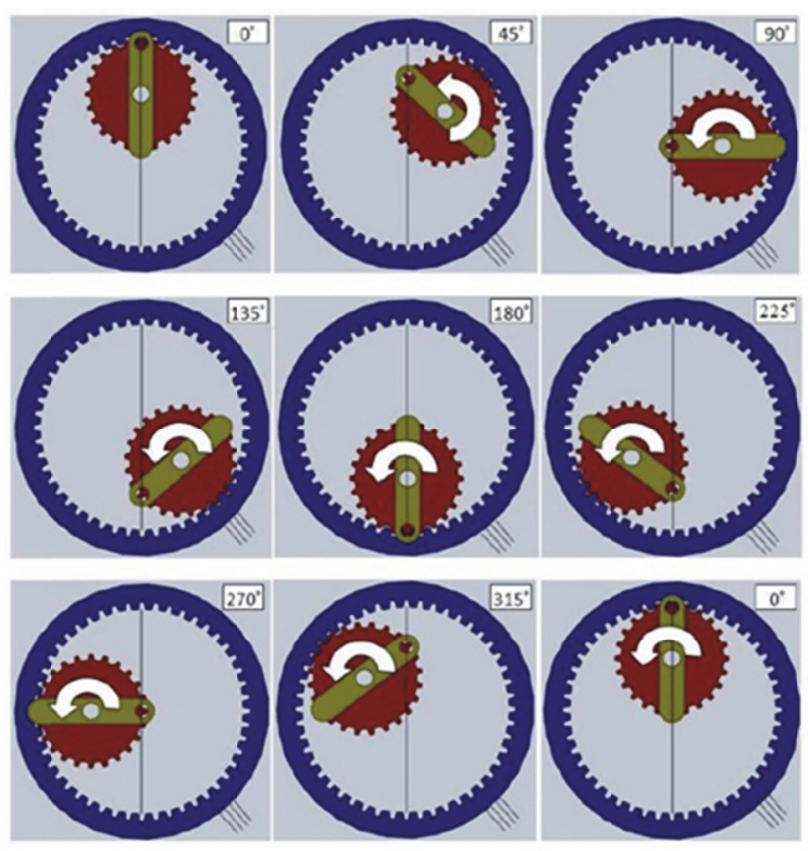

Fig. 11. Principle of operation of hypocycloid transmission [6].

Analysis of the motion of the working element indicates that it performs movement in which the speed can be described using the sine function, similarly to a slider mechanism. The parametric equation determining the point's position as a function of angle of rotation can be defines as follows:

$$
\begin{aligned}
& x(\alpha)=(R-r) \cos (\alpha)+r \cos \left(\frac{R-r}{r} \propto\right) \\
& y(\alpha)=(R-r) \sin (\propto)-r \sin \left(\frac{R-r}{r} \propto\right)
\end{aligned}
$$

\subsection{Benefits of applying a hypocycloid drive in a fuel pump}

The operational problems of pumps in common rail systems, described in the first two sections, indicated their high sensitivity to fuel quality as well as tendency for accelerated wear in the area of the drive due to lateral forces. The proposed solution of a pump with hypocycloid drive is free from these flaws and simultaneously makes it possible to utilize other beneficial features of the hypocycloid. Figure 12 presents a concept cross-section of the designed pump, 
which was modeled using Autodesk Inventor software. The pump is driven by the main shaft (1), in which the countershaft (2) is mounted in a manner enabling their reciprocal rotation. A toothed wheel with exterior toothing is found on the countershaft and meshes with toothed wheel (3), which is immobile and bolted to the pump's body. The drive shaft has bearings on the exterior surface of wheel 3, bearing 4. A mandrel (9) is mounted eccentrically in the countershaft, and the plunger (8) along with the guide element is connected to this mandrel via bearing and positioned so that it can slide in the cylinder (7). Furthermore, the countershaft has a support (5) with bearings in the pump's body - bearing (6).

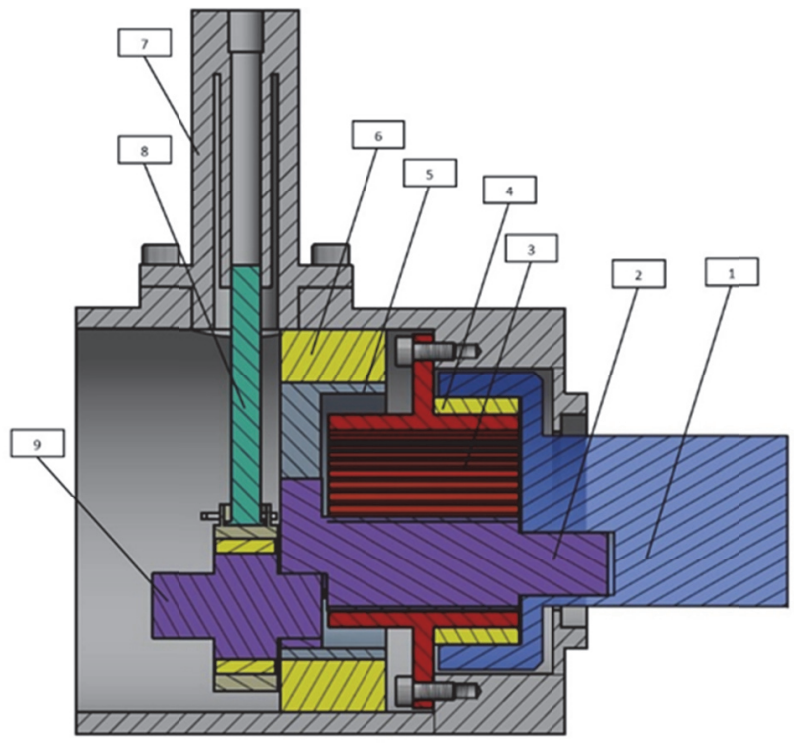

Fig. 12. Scheme of high-pressure pump with hypocycloid drive: 1 - main shaft, 2 - countershaft, 3 - toothed wheel with interior toothing, 4 - bearing of main shaft, 5 - support of countershaft, 6 - support bearing, 7 - cylinder of pumping section, 8 - piston (plunger) with guiding element, 9 mandrel.

One of the most important benefits of the pump's design is the high pitch of the working element, equal to the diameter of the large wheel's pitch circle diameter. In traditional CR pumps, the pitch of the working element is no greater than $7-8 \mathrm{~mm}$. For the module under consideration, with a transmission ratio of 1 and 40 teeth, the pitch of the working element will be $40 \mathrm{~mm}$. Multiplying the piston's pitch while maintaining its diameter makes it possible to obtain much greater discharge per work cycle. In practice, this solution leads to two benefits:

- the possibility of obtaining very small pump dimensions relative to discharge in comparison with conventional cam pumps,

- the possibility of significantly reducing forces present in the pump mechanism by using high discharge to generate high pressures by means of a simple, mechanical hydraulic amplifier. Besides reducing the pump's overall dimensions, reducing forces will make it possible to apply cheaper (poorer) constructional materials.
Another effect of high piston pitch is the possibility of easy utilization and control of the implosion effect. This effect is based on introducing a liquid or gas into a space and dissolving it in the volume of that space by increasing pressure (which reduces volume). During the injection process, when there is a pressure drop, gas is released from the liquid and has a beneficial effect on the fuel jet atomization process, improving fuel spraying. Thanks to increased pitch, and thus, greater sectional volume, the parameters of the air-fuel mixture can be controlled easily.

The problem of lateral forces in the drive system has been eliminated in the proposed solution. In the case of a cam drive, the lateral force on the piston reaches values up to $300 \mathrm{~N}$. Besides elevated wear in the cam - piston (plunger) area, unfavorable chamfering of the piston takes place, leading to increased wear of the cylinder's side surface and thus reducing the section's tightness. An additional guiding element loaded with lateral force is applied in many pumps, however this is an unfavorable solution due to the increased number of friction pairs and the inertia of moving parts. Moreover, a defective guiding system can be the cause of deteriorating pump parts, as shown by the example of $\mathrm{CP} 4$. In relation to the absence of lateral forces, it seems beneficial to apply ceramic engineering materials for contacting surfaces of the piston and cylinder. In the case where fuels of reduced quality or heavy fuels are pumped, hard ceramic surfaces contribute to eliminating the wear on the pistoncylinder pair. Besides the possibility of applying many other modern fuels, attention should be paid to the suitability of designs for fueling an engine with rapeseed oil and its esters. In the case of traditional pumps, during standstill, esters "glue" interoperating elements together, which is often the cause of many failures damaging the entire system, as shown in the example of vane blocking in the Continental pump, or sliding friction between the roller and cam, as in Delphi DFP1.

The applied drive solution should also increase the pump's resistance to heavy fuels. In the presented pump design, the pumping section was separated from the drive system, under the assumption that it would be lubricated using motor oil or transmission oil. Due to the piston's high pitch and the pumping section's length, it is possible to apply double labyrinth sealing along with a channel draining leaking fuel into injectors' overflow conduit. This will make it possible to achieve the minimum, acceptable leakage of drive oil into the lubricating fluid. Substituting fuel with lubricating oil will have a beneficial impact on the lifetime of interoperating elements, with regard to both sliding bearings and applied toothed wheels [10].

The absence of a return spring should also be counted as one of the pump's benefits. Pump solutions utilizing a cam system for each section have a return spring that ensures that the pusher is constantly pressed into the cam. Besides obviously increasing the weight of the system, the spring is an element that receives energy and gives it off in the form of heat to a small extent. In addition, considering a high number of cycles, return springs are susceptible to damage caused by material fatigue. The presented pump design is characterized by a 
journal-bearing joint for the mandrel and working element, so two-way movement is determined by the resultant of these two components.

The very high discharge from the pumping section that was achieved fits well into the latest trends in fuel injection systems. The concept injection systems mentioned in the second section are characterized by the pursuit of the minimum number of elements while maximizing the engine's economic and environmental indicators. The combination of high piston pitch and a direct control valve makes it possible to eliminate the fuel vessel entirely. In CR systems, the existence of a common fuel rail is a necessity, however it is problematic from the perspective of precise spraying control, above all, control of injected fuel, due to complex hydraulic phenomena. By using a direct-action valve, the start and end point of injection can be determined easily, and a conventional valve with the same design as a pressure regulator in a common rail can be used to adjust pressure. Such a system largely resembles a UPS assembly, nevertheless, the type of pump and control system are significant differences.

\subsection{Selected operating parameters of pump with hypocycloid drive}

The presented pump design has been filed under the patent application P.418961, which also contains reservations concerning the further development of the design, such as the application of engineering ceramics or the introduction of gas into the chamber for the purpose of obtaining the implosion effect. Preliminary strength calculations have been conducted and confirm the correctness of selected materials. Additional strength calculations using the finite element method were conducted using Femap software, running on the basis of the NX Nastran module. The countershaft is the element most under load in the system due to the complex state of flexural and torsional stresses. The authors created a model of the design in Autodesk Inventor software and conducted dynamic simulation of the assembly's operation on the basis of this model. Figure 13 presents the progression of loading force acting on the pump piston in the dynamic simulation. Pressure was set to $1500 \mathrm{bar}$, and the $75 \%$ of the section's volume was filled with fuel. In effect, a force of $5300 \mathrm{~N}$ acting on the piston was obtained. The rapid growth of force to the maximum value during the compression phase is due to the fluid's low compressibility. When pressure reaches 1500 bar, the valve is opened and a batch of fuel is pumped outside of the system. The force progression is similar to the curves obtained for cam pumps with the same compression pressure and piston diameter, in terms of the value and profile of the curve. Decidedly greater values were achieved, however, for the piston's linear speed, which reaches a maximum of $3.14 \mathrm{~m} / \mathrm{s}$. This speed is directly proportional to angular speed and to the distance of the center of rotation from the center of the working element (in a cam system - eccentric, in a hypocycloid - distance of the mandrel's axis from the axis of the wheel with interior toothing). The relationship between angular speed and speed of reciprocating motion is defined by the formula :

$$
V(\propto)=\omega r \sin (\propto)
$$

The increase of piston speed is linked to deterioration of the cylinder filling efficiency parameter due to elevated flow resistance, which is related to both elevated pumping resistance on conduits feeding the section and to the valve's dlesign. For this reason, it seems advantageous to apply new-generation directaction valves, which must be characterized by low flow resistance due to the two-way flow of compressed fluid. Due to the proportional dependency between speed and eccentricity, the hypocycloid system clearly benefits interoperating parts, particularly at low speeds. Increasing linear speed, according to lubrication theory, makes it possible to generate a layer of lubricating film in the piston-cylinder pair, which effectively separates the two interoperating elements. In relation to the absence of lateral forces which cause chamfering of the piston, very beneficial parameters of interoperation between the side surfaces of the cylinder and piston (plunger) are obtained.

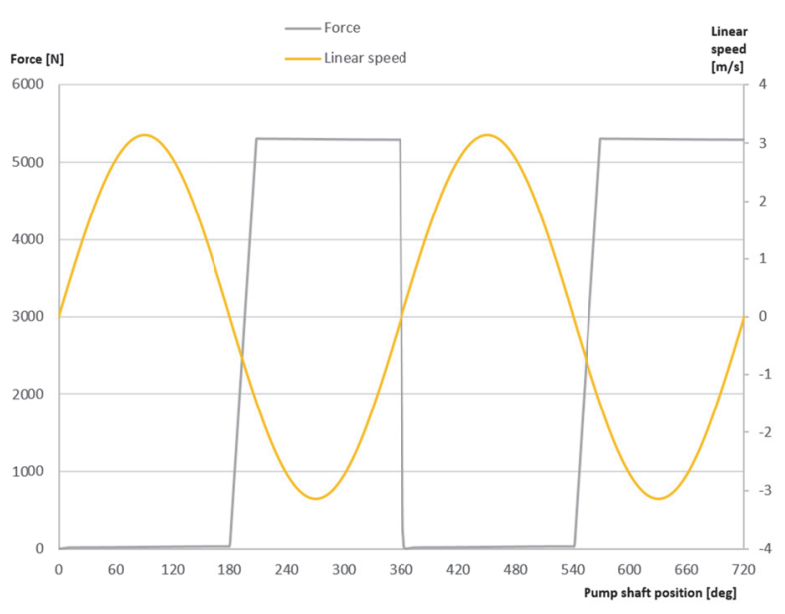

Fig. 13. Progression of force acting on the piston's face and piston's linear speed.

In order to determine power consumed by the pump, torque on the main shaft was determined. The value and progression of torque is presented in figure 14. The simulation accounted for friction losses between interoperating elements. The average torque required to drive the pump was calculated for the obtained curve. Based on this torque, knowing that the pump shaft was revolving at $1500 \mathrm{rpm}$, power consumption was determined to be $14.5 \mathrm{~kW}$. This parameter seems unfavorable compared to conventional solutions, however the fact that the discharge per shaft revolution is much higher, as demonstrated in the simulation, must be accounted for. It seems that it is much more representative to relate the volume of pumped fluid to the pump's power. Very similar indicators of both pumps' work were obtained as a result of comparing the given parameters. Therefore, it is possible to achieve favorable working parameters of an engine using an 
injection pump with hypocycloid drive. Further optimization of the pump based on the results of workstation tests will go in the direction of reducing internal friction, which will additionally improve the entire system's efficiency.

Table 1. Comparision between hypocycloid and CP4 pump.

\begin{tabular}{|l|c|c|}
\hline & Bosch CP4 & Hypocycloid pump \\
\hline $\begin{array}{l}\text { Input power } \\
{[\mathrm{kW}]}\end{array}$ & 3.95 & 14.51 \\
\hline $\begin{array}{l}\text { Unit discharge } \\
{\left[\mathrm{cm}^{3}\right]}\end{array}$ & $\begin{array}{c}0.3 \\
(100 \% \text { filling })\end{array}$ & $\begin{array}{c}1.15 \\
(75 \% \text { filling })\end{array}$ \\
\hline $\begin{array}{l}\text { Discharge to } \\
\text { power ratio }\end{array}$ & 0.076 & 0.079 \\
\hline
\end{tabular}

Figure 14 also presents the progression of lateral force in the mandrel - working element pair. Low values within the range of $10-5 \mathrm{~N}$ were obtained due to the systems vibrations. In the cam solutions presented earlier, for a cam-plate friction coefficient of 0.01 , this force reaches up to several hundred N. Reduction of this force also provides the possibility of applying cheaper materials, which work under elastohydrodynamic lubrication conditions in the mandrel - bearing pair of the working element, besides reducing the adverse impact on wear of elements. DLC (Diamond Like Carbon) coatings are currently applied to cams and pushers, which, due to their high hardness thanks to properties similar to diamond, is wear resistant. High production costs related to advanced technology and the need to employ additional machines are the disadvantages of applying such coatings. In addition, in the case of insufficient lubrication, the surface layer undergo abrasive wear, which leads to contact with the cam's core and seizing of interoperating pairs.

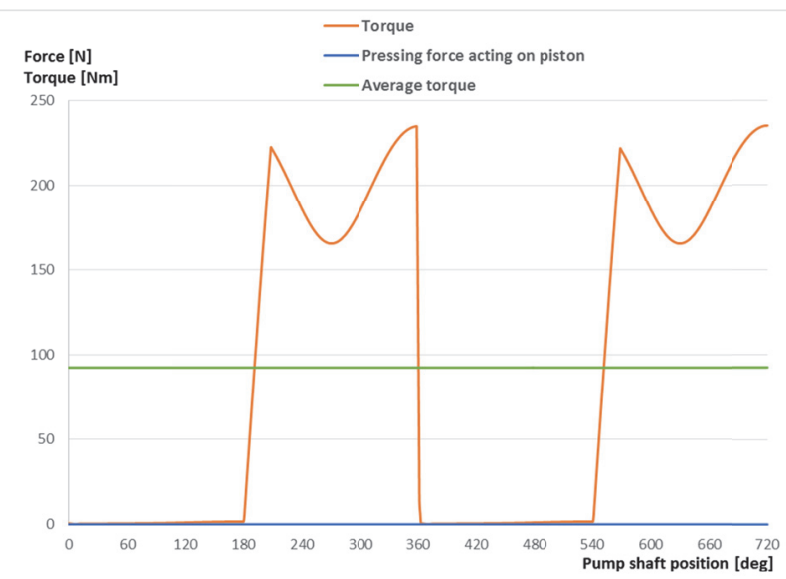

Fig. 14. Progression of pump's drive torque and lateral force acting on a piston and its linear speed.

\section{Summary}

Despite the dynamic development of spark ignition units, which are displacing Diesel engines on the passenger vehicles market as emissions standards become more strict, Diesel engines will continue to make up a large share of the total production of drive assemblies.
Injection systems have a significant role to play in improving their operating parameters. Due to the high precision of injection process control, with high pressure of fuel compression, these systems are characterized by sensitivity to the quality of applied fuel due to the large forces acting on the system's elements. Numerous design solutions are susceptible to damage resulting from defective design of a given element, besides damage generated by fuel of insufficient quality. In the case of pump defects, leading to the creation of filings with diameters below several micrometers, other elements of the injection systems are also damaged very frequently, which increases repair costs significantly. The modern CR pump should be characterized by resistance to improper fuel quality, high compression pressure and low power consumption [11].

The authors have proposed in their article a hypocycloid drive fuel pump. The benefits presented by the drive system are the advantages of the presented solution both in terms of durability and achieved environmental parameters. The pump uses a hypocycloid mechanism instead of a conventional cam to drive the pumping section, which is lubricated using a separate lubricating oil system. The high stroke of the piston relative to the overall dimensions of the pump optimizes the flow, contributing to the compact size and the reduction in the number of pumping sections even in multi-cylinder engines. This pump is part of the latest trends in the design of high pressure injection systems. The lack of lateral force contributes to reducing the wear of the walls of pumping section. Due to the different design of the propulsion system, the problem of wear of the cam-piston knob caused by the resulting lateral force, also contributes to the complete damage to the pumps. In addition, the simulations showed that the torque curve does not deviate from the parameters of modern pumps. The large piston stroke of the pump gives the opportunity to create a system where the fuel tank is completely eliminated, which greatly simplifies the engine's layout and contributes to the reduction of harmful hydraulic volume. The direction of further work should be to optimize the flow of fuel in the canals and valve sections.

\section{LIDER}

This article was financially supported within the project "New generation of common rail pumps" - Lider/015/273/L5/13/NCBR/2014, implemented within the LIDER Programme, financed by the National Centre for Research and Development, Poland.

\section{References}

1. Materiały szkoleniowe Centrum Szkolenia Motoryzacji Autoelektronika Kędzia.

2. W. Karpiuk, G. Kinal, R. Smolec, Combustion Engines 162, 988-995 (2015)

3. W. Urzedowska, Z. Stepien, Fuel Processing Technology 142, 403-410 (2016), DOI: 10.1016/j.fuproc.2015.11.001 
4. T. Osipowicz, T. Stoeck, Autobusy: technika, eksploatacja, systemy transportowe 16, 178-181 (2015)

5. D. Pietras, Polish Maritime Research 23, 58-63 (2016), DOI: $10.1515 /$ pomr-2016-0032

6. R. Priyesh, Doctorate Thesis (2014)

7. G.M. Szymanski, F. Tomaszewski, Proceedings of The 17th International Congress on Sound and Vibration (Cairo, 2010)

8. www.2microntech.com (2017)

9. S.W. Kruczyński, B. Chrupek, Zeszyty Naukowe Instytutu Pojazdów 4, 113-122 (2014)

10. J. Merkisz, J. Mizera, M. Bajerlein, L. Rymaniak, P. Maj, Experimental and Applied Mechanics 518, 102-107 (2014), DOI: 10.4028/www.scientific.net/AMM.518.102

11. K. Szwedzka, J. Gruszka, P. Szafer, IOP Conference Series-Materials Science and Engineering 145, $062007 \quad$ (2016), DOI: 10.1088/1757$899 X / 145 / 6 / 062007$ 